\title{
Una mezquita de «nueve bóvedas» en Córdoba. Estudio arquitectónico de un edificio desaparecido en $\mathbf{1 7 2 5}$
}

\author{
A "nine dome mosque" in Córdoba. Architectural \\ research about a building demolished en 1725
}

\author{
Antonio Jesús García-Ortega* \\ Universidad de Sevilla, España
}

Tras la conquista castellana de Córdoba, en 1236, la nueva parroquia de San Nicolás de la Ajerquía aprovechó como iglesia una pequeña mezquita junto al río Guadalquivir. El edificio, ampliado a mitad del siglo XVI y reiteradamente transformado a lo largo del tiempo, mantuvo la preexistencia islámica hasta las importantes reformas del período 1725-27, que supusieron su total demolición. Pese a que existen varias alusiones documentales de aquellos años y un dibujo a mano alzada de la planta conservado en el archivo parroquial, esta mezquita ha pasado prácticamente inadvertida en la historiografía especializada, quizás porque los escasos y ambiguos datos conocidos no permiten estimar su arquitectura. En este trabajo se analiza directamente el dibujo original, contextualizándolo con distintos planos y documentos históricos. Esto ha permitido formular una hipótesis sobre las dimensiones de la sala de oración de la mezquita, su orientación aproximada, así como sobre su conformación arquitectónica interior: una planta prácticamente
After the Castilian conquest of Córdoba in 1236, a small mosque next to the Guadalquivir River was converted into the parish church of San Nicolás de la Ajerquía. The building was extended until the mid-sixteenth century and repeatedly transformed over time. However, the ancient Islamic building existed until its demolition during the important reforms of the period 1725-1727. There are several documentary records of those years, and also a plan sketch preserved in the parish archive. However, this mosque has gone virtually unnoticed by the specialized historiography, perhaps because the limited and ambiguous data hinder a proper valuation of its architectural form. In this study the original drawing has been analyzed, contextualizing it with several plans and historical documents. This has produced a hypothesis about the size of the mosque's prayer hall, its approximate orientation, as well as its interior architectural organization: an almost square plan, subdivided into nine areas covered with vaults. Therefore, it could be

* El autor agradece la labor de los revisores anónimos de la revista Al-Qanțara, cuyas sugerencias han enriquecido sustancialmente el presente trabajo, así como la de los profesores Antonio Gámiz Cordo y Rafael Manzano Martos (Universidad de Sevilla).

1 Abū l-Baqā' al-Rundī, Lamento por la pérdida de Sevilla (poema de 1267), traducción al castellano en Bosch, Historia de Sevilla, p. 186. 
cuadrada, organizada en nueve ámbitos con cierta autonomía espacial y cubiertos con bóvedas. Seguiría en esto a un tipo de mezquita hace tiempo detectada por Creswell, que la denominó «nine-dome-mosque», y de la que sería el único ejemplo conocido en Córdoba.

Palabras clave: mezquita; bóveda; dibujo; Bāb al-Mardūm; Córdoba; Ajerquía. framed within a type of mosque detected long ago by Creswell, who called it "ninedome-mosque". The building would be the only known example of such architectural type in Córdoba.

Key words: Mosque; Vault; Drawing; Bāb al-Mardūm; Córdoba; Ajerquía.

Las moradas del Islam, arrasadas y desiertas, en jardín florido para la infidelidad se han convertido. Alli, sin otra cosa en ellas que campanas y cruces, las mezquitas iglesias han devenido ${ }^{1}$

Abū 1-Baqā’’ al-Rundī

El lamento del poeta por la pérdida de las ciudades de al-Andalus, nos evoca la frecuente reconversión a iglesias de los lugares de oración del Islam. Se trataba de una operación realizada con elaborado ritual pero, al menos en un primer momento, con escasísimas transformaciones materiales en el edificio, efectivamente poco más que «campanas y cruces». Así en Córdoba, el 29 de junio de 1236, el conquistador castellano no dudó en consagrar como Catedral la gran Mezquita de los Omeyas ${ }^{2}$, a la que seguirían muchas de las mezquitas menores de la ciudad, convertidas en improvisados contenedores para iglesias parroquiales o conventuales ${ }^{3}$; también, más de una acabaría perdiendo el uso religioso ${ }^{4}$.

La gran mayoría de las mezquitas de barrio no nos han llegado, y es difícil identificar las subsistentes en los documentos islámicos.

2 Sobre el ritual, véase Bueno, "Fuga Demonium". Las primeras obras y transformaciones cristianas del edificio son tratadas en Ecker, "The Great Mosque of Córdoba". Para el coetáneo caso sevillano, Laguna, "La aljama cristianizada".

${ }^{3}$ Esto permitió alojar inicialmente las nuevas sedes parroquiales, retrasando hasta casi el final de la centuria la construcción de iglesias ex-novo (Nieto, Historia de la Iglesia, pp. 370-371). Sobre los procesos de instauración y dotación de las parroquias y su importante papel en la nueva organización religiosa y administrativa de la ciudad, véase Ecker, "How to administer a conquered city". Sobre el caso sevillano, Montes Romero y Valor, "De mezquitas a iglesias".

${ }^{4}$ Así, en 1271, la Iglesia cordobesa permuta el solar de una mezquita por un olivar (Nieto, Corpus mediaevale, p. 204). Además de su mero destino inmobiliario, por ejemplo, en Sevilla se dieron tres para sinagogas judías (Ecker, "The conversion of Mosques"). 
Las de extramuros desaparecerían con el gran receso urbano provocado por la fitna ${ }^{5}$, que despobló todos los arrabales excepto los de la Ajerquía (al-ŷiha al-šarqiyya), un amplio sector en el flanco oriental. Aquí tenemos dos alminares reaprovechados en las parroquias medievales de Santiago y San Lorenzo, este último poco conocido. En el núcleo principal de la ciudad, la Villa (al-qașaba al- 'atīqa), quedan la Mezquita aljama y la convertida en iglesia de Santa Clara, además del alminar de la iglesia de San Juan (Fig. 1).

A esta escasa nómina habría que sumar en la Ajerquía un edificio más. Se trata de una mezquita de barrio contigua a la desaparecida muralla sur, lindante con el río, que sobrevivió casi cinco siglos a la conquista cristiana, gracias a su reconversión como iglesia parroquial de San Nicolás de la Ajerquía, hoy en ruinas (Fig. 2). Un trabajo de recopilación documental de $\mathrm{M}$. Nieto ${ }^{6}$ dio noticia de su existencia, transcribiendo una breve descripción de 1727 recogida en el Libro de Bautismos parroquial (años 1707-1727, vol. 10, fol. 451), alusiva precisamente a unas reformas que supusieron su demolición. El texto se acompaña de un esquemático dibujo a mano alzada de la planta del edificio, tal y como era antes de las obras, en el que la sala de oración islámica hacía las veces de cabecera.

Pese a estas evidencias, la mezquita ha pasado prácticamente desapercibida en la historiografía especializada, quizás porque lo poco conocido no facilita su identificación y estudio ${ }^{7}$. Es necesario recabar y analizar detenidamente todos los indicios documentales, contextualizándolos y poniéndolos en relación con el dibujo de la iglesia. Incluso este tiene aún pendiente un estudio riguroso, abordándose aquí a partir del propio original, reproducido digitalmente por primera vez (Fig. 3) ${ }^{8}$. La investigación planteada profundiza en

${ }^{5}$ La mezquita de El Fontanar se saquea por entonces, en paralelo al despoblamiento de los arrabales occidentales. En los septentrionales se ha localizado un oratorio del siglo X, bajo la estación de autobuses (Luna y Zamorano, "La mezquita de la Antigua finca El Fontanar"; Calvo, Urbanismo en la Córdoba islámica).

${ }^{6}$ Nieto, Corpus mediaevale, p. 265.

7 Además, en Córdoba se perdieron fuentes documentales cristianas como las $\mathrm{Ca}$ pitulaciones o el Libro de Repartimiento, que podrían haber sido de utilidad, y tampoco disponemos como en Granada de libros de habices. Quizás una revisión de las fuentes islámicas, considerando lo aquí aportado, pudiera arrojar nueva luz.

${ }^{8}$ Se agradecen las facilidades de consulta y reproducción de los responsables de la iglesia parroquial de San Francisco, donde hoy se custodia el Archivo de la desaparecida parroquia de San Nicolás de la Ajerquía (APSN). 


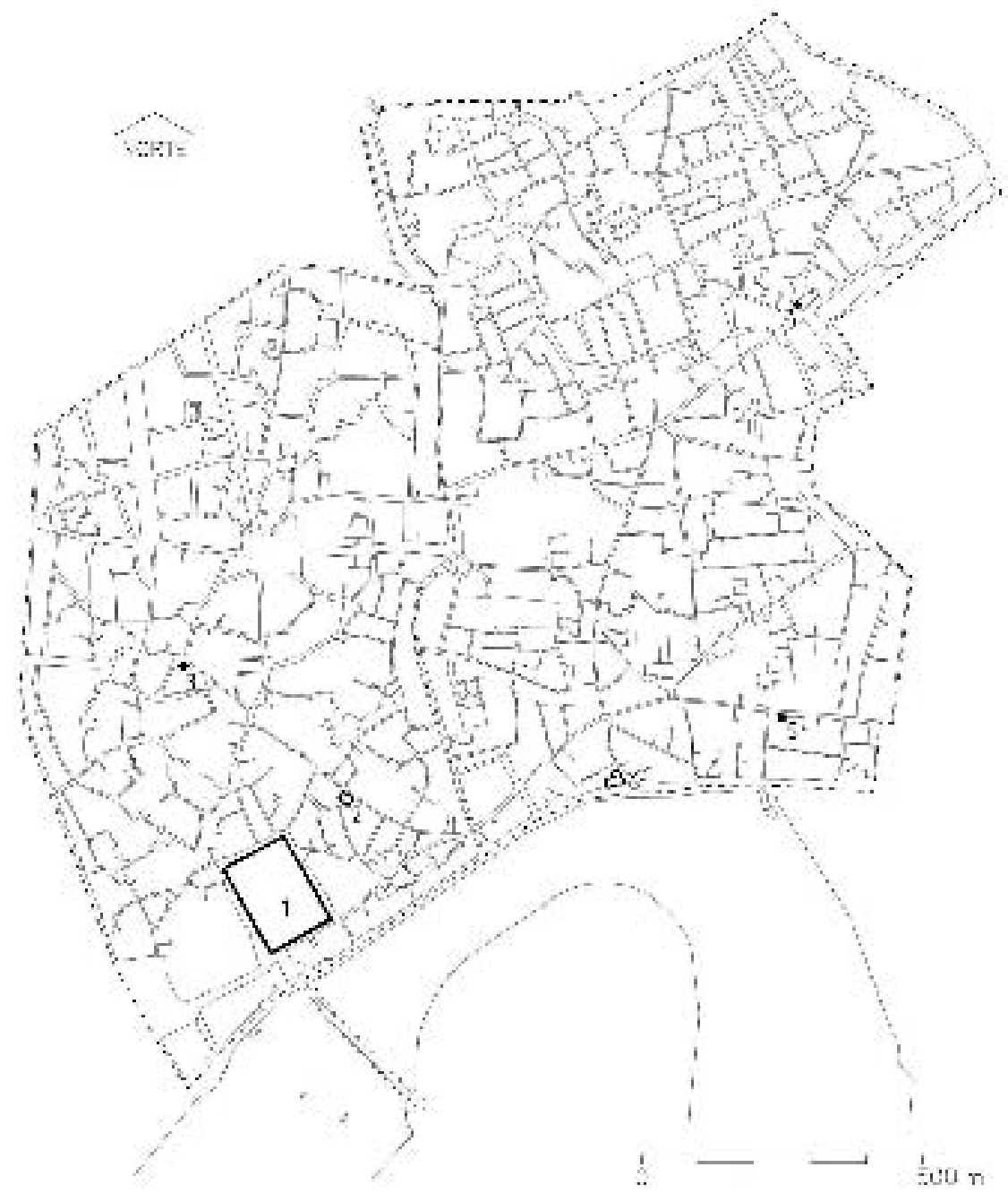

Figura 1. Plano actual del Casco Histórico de Córdoba, omitiendo crecimientos cristianos. Sectores de la Villa (izquierda) y Ajerquía (derecha)

1. Mezquita aljama.

2. Mezquita de Santa Clara.

3. Alminar de San Juan.
4. Alminar de San Lorenzo.

5. Alminar de Santiago.

6. Solar de la mezquita de San Nicolás de la Ajerquía

Al-Qanțara XXXIII 1, 2012, pp. 83-106 ISSN 0211-3589 doi:10.3989/alqantara.2010.003 


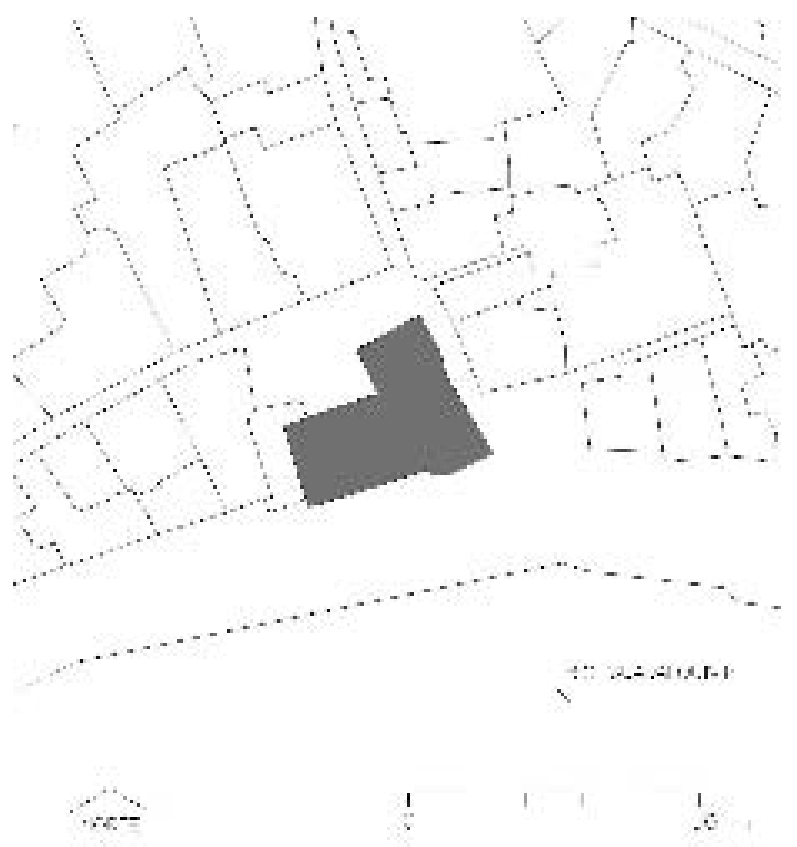

Figura 2. Solar de la antigua parroquia de San Nicolás de la Ajerquía, grafiado en el parcelario actual

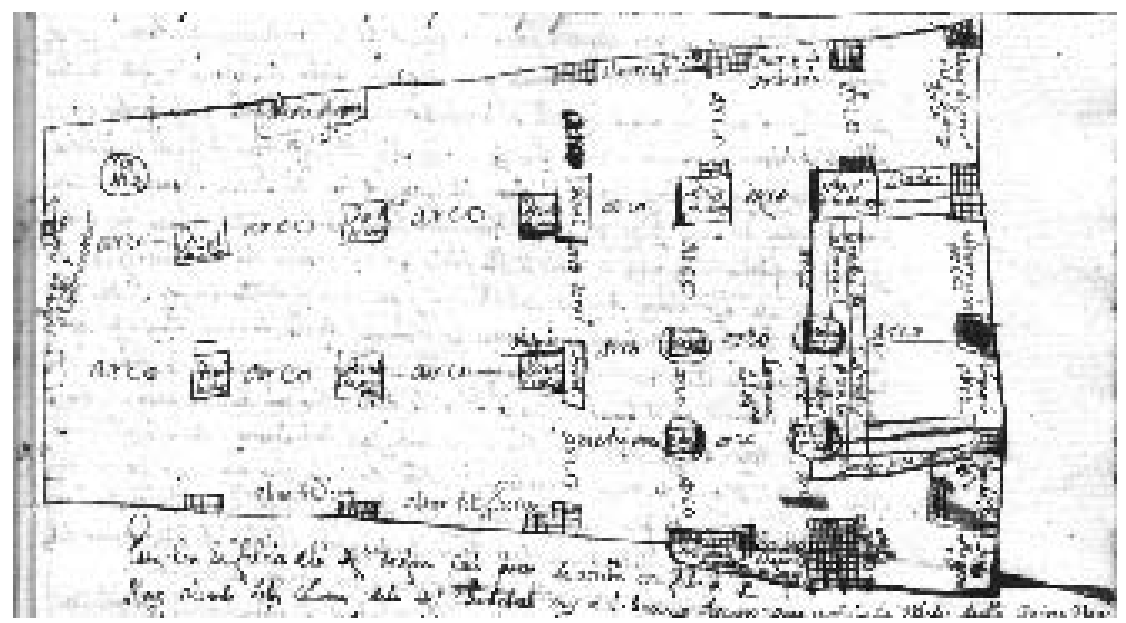

Figura 3. Dibujo de la iglesia según se encontraba en 1725. APSN, Libro de Bautismos 1707-1727 (vol. 10), fol. 451 
el propio Libro de Bautismos, cuya información es más amplia que la transcrita por M. Nieto, así como en distintos documentos del Archivo de la Catedral de Córdoba (ACC), el Archivo Histórico Municipal (AHM) y del Archivo General del Obispado (AGO). También, la particular ubicación del edificio le hizo formar parte de la fachada urbana meridional, la más significativa y dibujada desde tiempos bajomedievales. Así, en 1567 Anton van den Wyngaerde, queriendo representar en su vista general la parroquia de S. Nicolás de Aceçio, nos dejó sin saberlo el único testimonio del volumen de la mezquita, aunque ya convenientemente camuflado en el de la iglesia ${ }^{9}$ (Fig. 4).

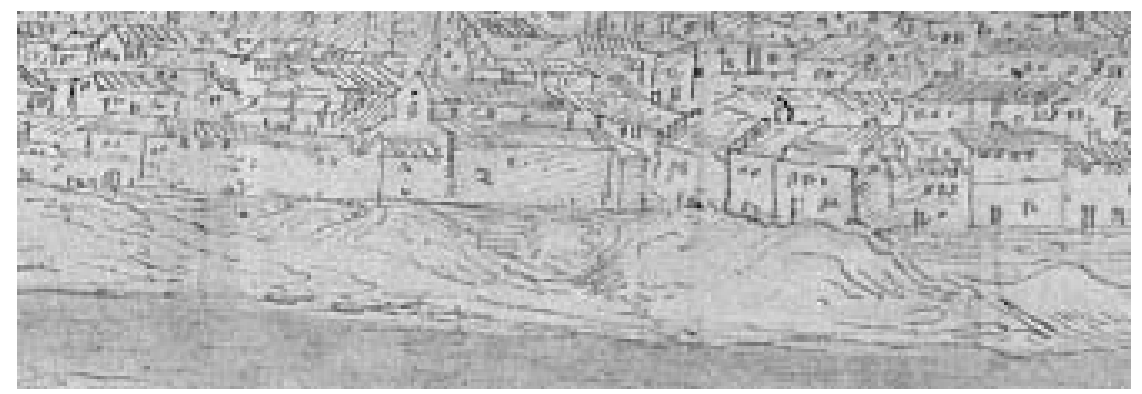

Figura 4. Detalle de la iglesia en la vista de Córdoba de Anton van den Wyngaerde (1567), Victoria and Albert Museum (PSA, FF 1567), Londres

\section{Notas documentales sobre el último oratorio de la Ajerquía}

El 23 de julio de 1723, D. Francisco Blanco de Zea, párroco y Rector de San Nicolás de la Ajerquía, pide la reforma y mejora de la iglesia al obispo D. Marcelino Siuri, aprovechando una visita del prelado. Tiempo después, en el mes de marzo de 1725, esto será recordado y anotado por dicho párroco en el Libro de Bautismos:

[...] se remediassen grandes faltas e irreberencias que la dicha $\operatorname{Ig}^{\mathrm{a}}$ desde su primera formazion y fundazion tenía. Así en la nave Maior, por estar torzida,

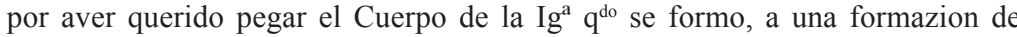

${ }^{9}$ Es un dibujo a plumilla y aguada en tonos sepias y azulados (Victoria and Albert Museum (PSA, FF 1567), Londres). 
arcos que en aquel sitio se hallaron, que parecia favbrica de Moros o Mezquita menor de su tiempo al modo de la Catedral mas mui bajos y obscuros $[\ldots]^{10}$

El documento, desconocido e inédito hasta la fecha, es claro en cuanto a cómo se había formado el edificio: un cuerpo de naves adosado a una «formazion de $\operatorname{arcos}[\ldots]$, que parecia favbrica de Moros», existente en aquel lugar. Estamos, pues, ante la primera alusión escrita a la mezquita, integrada en una iglesia a punto de ser reformada. Como consta en la documentación parroquial y municipal, las obras comenzaron el 13 de marzo de 1725. Una vez concluidas, el 7 de febrero de 1727, el párroco quiso dejar testimonio póstumo, "para memoria», de la conformación de la iglesia previa a las obras y de algunas circunstancias relacionadas con las mismas, como el traslado provisional al cercano Hospital de la Santa Caridad o algunos hechos milagrosos acaecidos ${ }^{11}$. Para ello aprovecha de nuevo el Libro de Bautismos:

Como consta en el folio 434 Buelta por la indecencia de la Ig de esta Parroq ${ }^{\mathrm{a}}$ de los Santos Nicolas y Eulogio y su mala formazion, nos passamos al Hospital de la Santa Caridad sito en los límites y jurisdiccion de ella cuia obra se comenzó el día 13 de el mes de Marzo el año de 1725 y para algun modo poder explicar la forma que tenia el dicho templo lo pintare aquí para memoria. Esta era la fabrica de la Ig $^{\mathrm{a}}$ antigua cuia parte de arriba era fabrica de Moros al

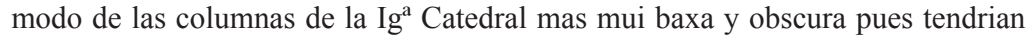
las bobedas de ella quatro varas de alto y nada mas. La fabrica del cuerpo de abaxo de la Ig es fabrica del Sr. D. Leopoldo de Austria Obispo que fue de esta Ziud $^{\text {ad }}$ de Cor $^{\text {ua }}$ quien labro las mas de las Parroquias. Y esto consta por averse

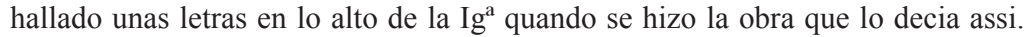
Esto supuesto el día 13 de dicho mes de Marzo de 1725 se comenzo la obra y duro el acabarla por la parte de adentro de ella hasta oi siete de Febrero de 1727

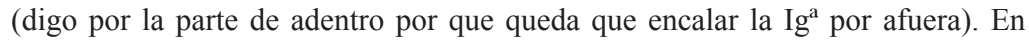
cuia obra an sucedido cosas maravillosas [...] y fue que subiendo Pedro Fausto por un palo que llaman Esparrago que sirbe de Escalera, el qual estaba en medio de la Capilla maior y estando como ocho varas de alto se solto de él y caio avajo [...]. A los ocho dias vino a la obra como sino obiera padecido golpe alguno [...]. Otro prodigio acontecio con el dicho Pedro Fausto que era oficial de la obra y fue que estando derribando los arcos fabrica de moros se desgajo una piedra sin verla y le dio tan cruel golpe al dicho Pedro Fausto que lo alejo mas

10 APSN, Libro de Bautismos 1707-1727 (vol. 10), fol. 434vta.

${ }^{11}$ Esto es algo llamativo, quizás fruto del convencimiento del párroco del acierto de su empresa, merecedora de la protección divina. Las obras habían supuesto numerosas gestiones, un prolongado traslado de la parroquia, y una cuantiosa suma aportada principalmente por el obispo. 
de tres varas $[\ldots]$ y ni una señas en su cuerpo le hizo levantandose sano como sino ubiera tal sucedido $[\ldots]^{12}$.

El texto explicita que el edificio constaba de una parte de «arriba» o cabecera (antigua mezquita), y el «cuerpo de abaxo», unas naves del episcopado de D. Leopoldo (1541-57). De la primera se destaca su marcada apariencia islámica, con «columnas» similares a la de la Mezquita-Catedral, que sostendrían una «formazion de arcos» y «bóvedas de quatro varas de alto». Esta dimensión debe de ser estimativa, ya que el propio documento explicita que el oficial Pedro Fausto cae desde «ocho varas de alto», cuando subía a la Capilla Mayor. El relato del otro accidente tiene también gran interés, ya que testifica con claridad la demolición de la construcción islámica, para su reedificación: «[...] estando derribando los arcos fabrica de moros se desgajo una piedra». El cuerpo de naves adosado debió de sufrir al menos un remozado general, ya que en el texto se alude que aún

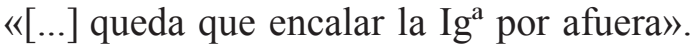

El párroco realizó también un dibujo de la planta del edificio, cuyo contenido es totalmente coherente con el texto (anterior Fig. 3). Sus dimensiones son de $18,5 \mathrm{~cm} \times 11 \mathrm{~cm}$, está hecho a mano alzada con tinta sepia, íntegramente a líneas, y sin precisar escala. Se representa la planta de una iglesia de tres naves, con grandes pilares cuadrados rotulados como «postel de arcos», formalizando tres vanos. La cabecera tiene, extrañamente, cuatro naves, y en ella aparecen los cuatro únicos elementos rotulados como «columna», sobre los que cabalgan arcos en las dos direcciones ortogonales, que sostendrían las bóvedas a las que alude el texto. En el costado sur llama la atención un pequeño ámbito al que se accede por un «arco», utilizado como «altar de animas» y «Sacristía de animas» ${ }^{13}$, constituyendo un saliente de la fachada.

Las descuadres del perímetro daban una iglesia «torzida», como se precisa en la primera descripción de 1725. El costado sur del edificio estaría libre, y al menos parcialmente el oeste y norte, que cuentan con accesos. Sin embargo al este pudo existir algún cuerpo anejo, al aparecer en el dibujo una extraña línea a modo de prolongación del lienzo sur; este espacio absorbería los descuadres que aún hoy existen en el límite oriental del solar.

12 APSN, Libro de Bautismos 1707-1727 (vol. 10), fol. 451.

13 Esta, según consta en el fol. 451vta. tenía antes de la reforma una vara de largo, lo que nos orienta sobre las dimensiones de este espacio y del propio edificio. 
Pese a todo, el objeto principal del dibujo no es el edificio como tal, obviándose, por ejemplo, el grosor de los muros perimetrales. El interés se pone en la organización interior y el destino de cada espacio, algo que queda patente en el folio 451vta., donde se detalla la nueva ubicación tras las obras de los altares y demás espacios cedidos, verdadera preocupación del párroco. Solo así se entiende que se quiera dejar constancia, ya en 1727 , de una conformación desaparecida dos años antes.

Otros documentos reiteran todas estas circunstancias y en particular explicitan que las obras de reedificación se limitaron a la cabecera. Así, el del 22 de enero de 1727 se invita a las autoridades a los actos religiosos de reapertura de la parroquia, una vez «[...] concluyda

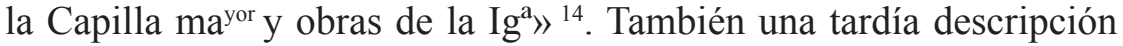
de 1773 especifica que el traslado parroquial duró «[...] dos años menos tres meses [...] por causa de la obra de la Capilla Mayor, siendo su artifice Fran ${ }^{\text {co }}$ López, que dio traza» ${ }^{15}$. Esta «traça» para una nueva cabecera supondría el fin de la última mezquita de la Ajerquía que quedaba en pie.

\section{De mezquita a iglesia: las sucesivas transformaciones del edificio}

La mezquita se reutilizaría como iglesia desde el primer momento de la conquista, reorientando el culto a levante según la costumbre cristiana. En el interior se realizarían algunas adaptaciones menores ${ }^{16}$, incorporándose elementos muebles, ornamentos litúrgicos, etc., o el «altar maior» y las «gradas» que vemos en el dibujo de 1727. El mihrāa b debió de suprimirse, algo habitual en elementos que recordaran el pasado islámico del edificio ${ }^{17}$, accediéndose por su arco al «altar de animas».

La pequeña iglesia resultante se ampliaría durante el episcopado de D. Leopoldo de Austria (1541-1557) con un cuerpo de tres naves a poniente, quedando la antigua mezquita como cabecera. Por el

${ }^{14}$ AHM Ref. C-0100, doc. 011.

${ }^{15}$ ACC Colecc. Vázquez Venegas, vol. 260, fol. 320r.

${ }_{16}$ Sobre estas actuaciones primeras en las mezquitas cristianizadas, véase Bueno, "Fuga Demonium", p. 273.

${ }_{17}$ Calvo, "La mezquita de Bāb al-Mardūm", pp. 321-323. 
plano de 1727 sabemos que consistían en dos líneas de arcadas sobre «posteles» (pilares cuadrados), y con una luz libre sustancialmente mayor que en la parte antigua. En la zona de contacto, las arquerías añadidas no apoyan sobre el antiguo muro oeste de la mezquita, sino en unos pilares construidos al efecto. Para comunicar los dos ámbitos, nuevo y viejo, se perforaría dicho muro, dando lugar a los extraños pilares en «T» del dibujo, que tienen incluso una línea marcando la discontinuidad de las fábricas.

Este edificio quedó recogido poco después en la vista urbana de Wyngaerde (1567), que nos precisa su volumetría y huecos, destacando la ausencia de puerta en la fachada del río (anterior Fig. 4). La resolución de las cubiertas estableció continuidad formal entre nuevo y viejo, quedando el volumen islámico camuflado bajo un único y largo faldón de la nave lateral sur, que se extiende hasta la cabecera. De ella sobresale un pequeño cuerpo, que se corresponde en el siglo XVIII con la «Sacristía de animas» y el «altar de animas», delatando la antigüedad de este particular volumen.

La iglesia llegaría a 1725 tal y como la vemos en el dibujo estudiado. La fachada sur seguía sin acceso, la del oeste tenía la «puerta maior», y en la del norte había una puerta a la sacristía y otra al exterior, posiblemente al cementerio parroquial ${ }^{18}$. Su cabecera, antes de reedificarse, sobreelevaba con unas gradas la zona del presbiterio y el sagrario; también perimetralmente tenía distintos altares bajo «arco» constituyendo una llamativa sucesión de nichos murales, quizás de origen islámico.

En 1753 se volvieron a realizar obras para corregir los importantes descuadres del cuerpo de naves, que estrechaba de este a oeste ${ }^{19}$. Por ello se solicitó al Ayuntamiento la rectificación de la alineación sur, lo que permitiría ensanchar los pies «[...] tres varas menos tercia proporcionalmente repartidas en sus dos gualderas [...] para que por la parte proxima a el Rio se tome de sitio hasta vara y tercia con lo que quedara dicha Iglesia proporcionada en su todo» ${ }^{20}$. Esto impli-

${ }^{18}$ En el fol. 451vta. del Libro de Bautismos se alude a «seys sepulturas» (APSN).

${ }_{19}$ El obispo D. Miguel Vicente Cebrián, fallecido en 1752, incluyó en su testamento la financiación de las obras (Gómez, Catálogo de los Obispos de Córdoba, vol. II, p. 803).

${ }^{20}$ Expediente municipal de julio de 1753, titulado Sobre dar un sitio a la Iga de $S^{n}$ Nicolas de la Ajerquia para su ensanche (AHM Ref. C-766/24). La "vara" utilizada sería la castellana $(83,59 \mathrm{~cm})$, medida oficial del Reino desde 1568 (García, La legua náutica, p. 68). 
caba realinear las dos fachadas laterales, pero sólo se pide licencia para un tramo de unas veinte varas de la contigua al río, que afectaba a dominio público, ya que la fachada opuesta lindaría con el cementerio parroquial.

El informe del maestro mayor de obras incluyó un plano reflejando la regularización prevista, así como la ejecución de un pretil en el borde del río y el achaflanamiento del saliente generado a los pies de la iglesia (Fig. 5). De esta tan solo se representa la mitad sur del antiguo cuerpo de naves, el mismo que fue dibujado en el plano de 1727, y que subsistió a las reformas de entonces. Anexada a levante debía de estar la nueva cabecera que sustituyó a la mezquita, que no recogió el plano. Por la geometría actual de la parcela cabe suponer que las obras previstas, y consiguientemente las realineaciones, se llevaron a cabo.

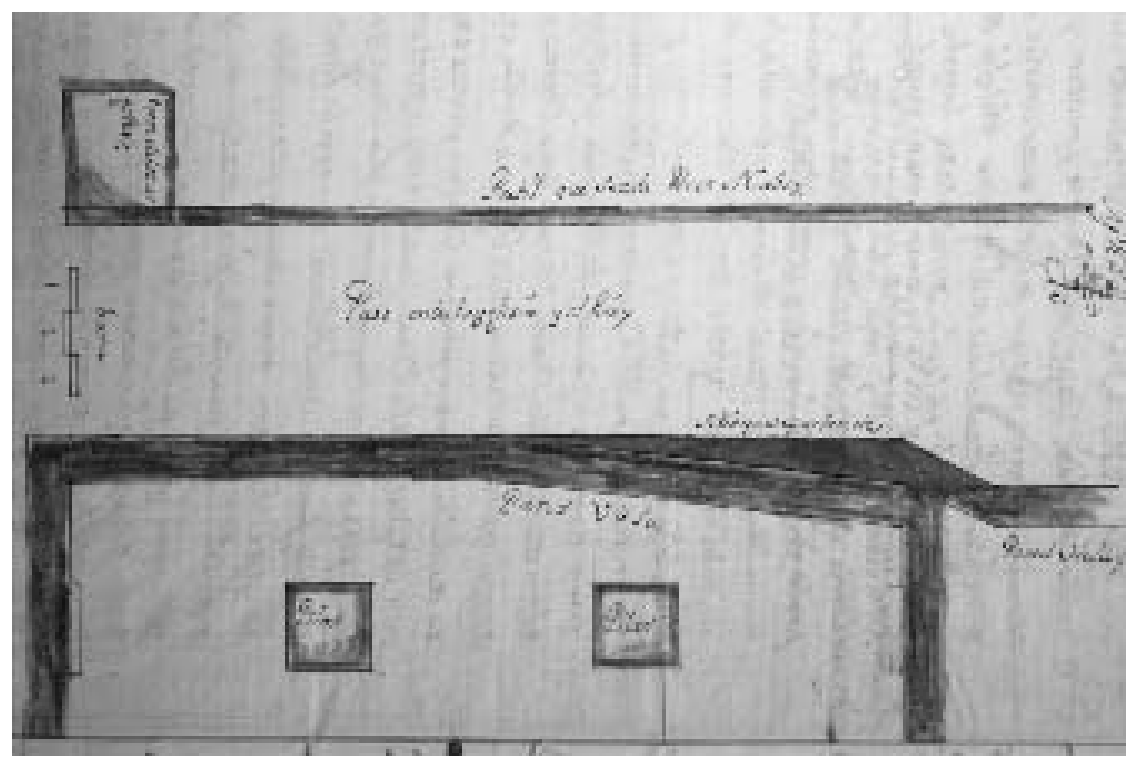

Figura 5. Cambio de alineación de la iglesia (1753). AHM, Ref. C-766/24 (plano con el «Sur» arriba)

El cementerio parroquial desaparecería en los años de la ocupación francesa, figurando ya como «Plaza de S. Nicolás del Río» en el plano de Karwinski (1811), que muestra también la definitiva 
clausura con edificaciones de todo el hastial de poniente. Según T. Ramírez ${ }^{21}$ en 1836 se volvieron a hacer obras en la iglesia, que se encontraba en estado ruinoso y sin cubierta en las naves como recogió un grabado de Taylor (1825-32) ${ }^{22}$. El edificio ya remodelado aparece en una litografía de Parcerisa $(1855)^{23}$, y en la vista aérea de A. Guesdon (h. 1853-55) ${ }^{24}$. Salvo reparaciones menores, la iglesia no tuvo más obras hasta su abandono en el año 1877, trasladándose la parroquia al desamortizado convento de San Francisco ${ }^{25}$.

El edificio actualmente es privado y está abandonado, quedando unos muros perimetrales con una cubrición de chapa y dos portadas laterales (Fig. 6). Al norte, en lo que fue sacristía, subsisten también las ruinas de una modesta construcción de dos plantas, ya sin tejado. El conjunto está incluido como «edificación religiosa» en el Catálogo de Bienes Protegidos del Conjunto Histórico de Córdoba ${ }^{26}$, permi-

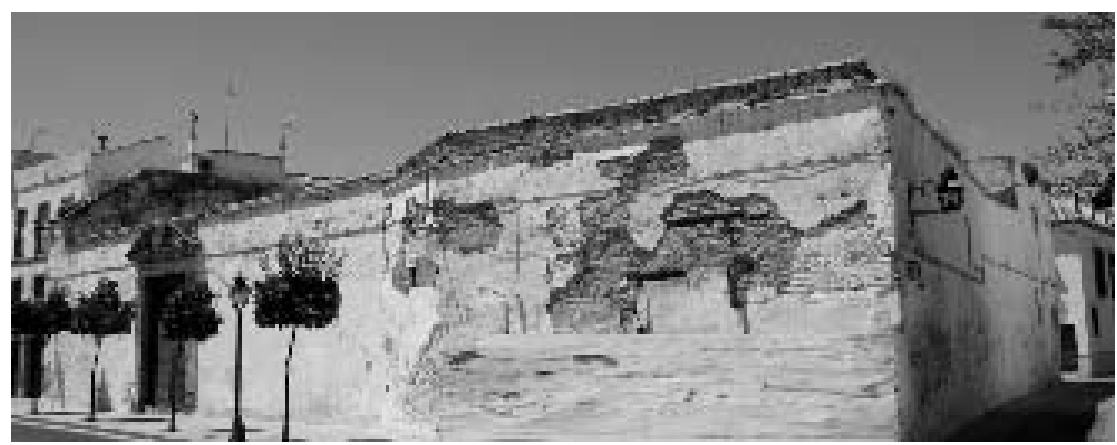

Figura 6. Restos actuales de la iglesia de San Nicolás de la Ajerquía, vista desde el sureste

${ }^{21}$ Ramírez de Arellano, Paseos por Córdoba, vol. I, p. 204.

22 Taylor, Voyage Pittoresque en Espagne, vol. I, lám. 24 titulada Vue de Cordoue. Cours du Guadalquivir (I.J. Taylor, dib. y Pye, grab.). Colección particular de D. Eduardo Páez López (CPEPL).

${ }_{23}$ Madrazo, Recuerdos y bellezas de España, vol. VIII, lám. sin núm. titulada Vista de Córdoba desde los Mártires (F.J. Parcerisa, dib. y lit. y J.J. Martínez, edit.), CPEPL.

${ }^{24}$ Guesdon, L'Espagne a vol d'ouaseau, lám. sin núm. titulada Vue prise au desaus du Guadalquivir (A. Guesdon, dib. y lit., y F. Delarue, edit.). Ejemplar del Museo de Bellas Artes de Córdoba. Sobre la técnica y fidelidad gráfica de las láminas, véase Gámiz, "Paisajes urbanos vistos desde globo".

${ }^{25}$ Cuentas de fábrica 1841-1876 (APSN). El traslado de la sede parroquial consta en un documento de 1877 (APSN).

${ }^{26}$ Documento urbanístico aprobado definitivamente el 8 de Mayo de 2003. Ficha EA-32, c/ Badanas, 22. 
tiéndose su reedificación como «equipamiento» con una nueva alineación de la fachada sur. En el solar podrían aún quedar restos islámicos, ya que la escasa altura interior de la cabecera en 1725 apunta a que la ampliación renacentista sobreelevó el nivel original, preservando los arranques de la mezquita de las demoliciones entonces realizadas.

\section{La mezquita dibujada en el documento de $\mathbf{1 7 2 7}$}

Estudio de la planta: ámbito, dimensiones y orientación

El ámbito de la sala de oración islámica puede reconocerse analizando el dibujo de 1727. Su costado sur lindaría con el espacio público, antes de añadirse la «Sacristía de animas» y el «altar de animas»; el borde este coincidiría con el límite de lo dibujado; y el oeste estaría en la duplicidad de «posteles», que marcan la zona de contacto del cuerpo de naves adosado en el siglo XVI. El límite norte también se señala por unos descomunales «posteles» con pilastras adosadas, que serían los restos del antiguo muro de la sala. Esta se nos presenta, pues, como un espacio cuadrangular, en cuya zona central aparecen exentos los cuatro únicos pilares rotulados en el dibujo como «columnas» (Fig. 7). La nave

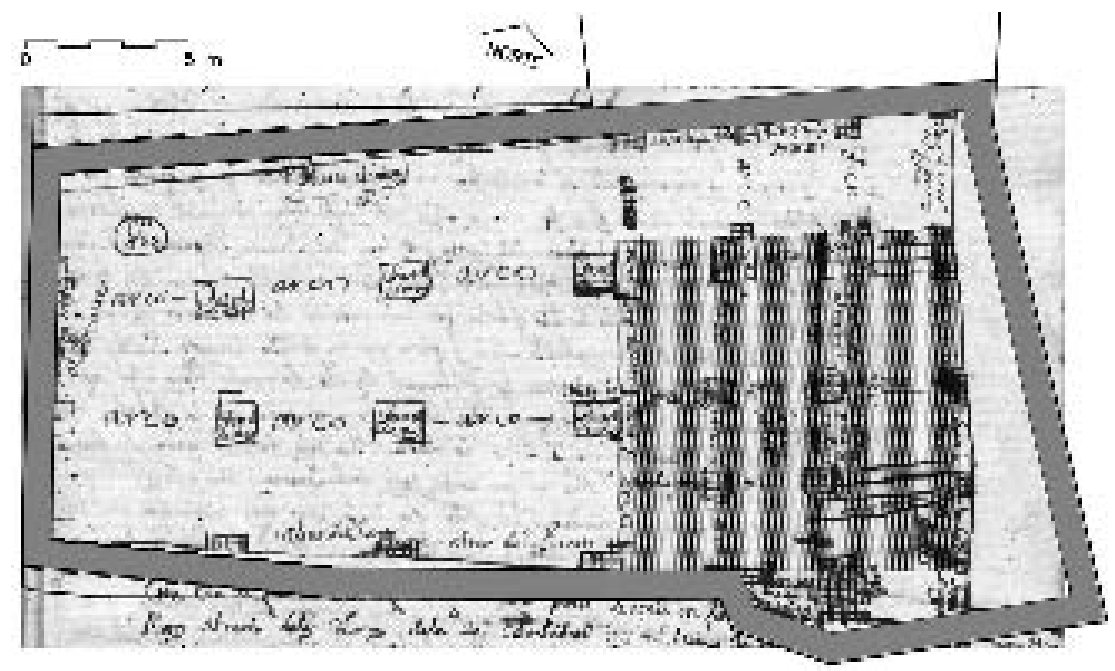

Figura 7. Ámbito estimado para la sala de oración (trama gris) e insertado del dibujo en la parcela actual corregida: alineaciones actuales (línea continua) / rectificación de alineaciones de 1753 (línea discontinua) / grosor de muro (tono gris) 
más septentrional pudo añadirse en la ampliación del siglo XVI, o tal vez incluso provenir de un antiguo pórtico islámico abovedado, dada la existencia de arcos transversales.

Las dimensiones pueden estimarse a partir de la documentación analizada y la planimetría histórica urbana, que demuestra que los límites parcelarios no cambiaron desde el expediente de realineación de $1753^{27}$. Las variaciones especificadas en este se dibujan en el solar actual ${ }^{28}$, obteniéndose las direcciones originales de las fachadas laterales y, en definitiva, el perímetro del conjunto parroquial de 1727. En este ámbito se insertará el dibujo estudiado ${ }^{29}$, aplicándose para su ajuste factores de escala que corrigen las desproporciones derivadas de su realización a mano alzada. El cuerpo de naves se afecta por uno en la anchura y por otro diferente longitudinal, éste para ajustar su longitud a las veinte varas especificadas en el plano de 1753. En la inserción de la cabecera, antigua mezquita, se adopta el mismo escalado para las anchuras, y longitudinalmente el necesario para su ajuste al espacio disponible, siendo el punto más restrictivo el ángulo noreste. Esto deja en el costado de levante un residuo triangular, de destino desconocido, y que ya insinúa el propio dibujo de 1727 por un extraño trazo que prolonga la fachada sur (anterior Fig. 7).

Se obtiene así una iglesia que se adecua al solar actual, corregido con la realineación de 1753. Parte de ella es la sala de oración de la mezquita, un ámbito prácticamente cuadrado $(9,60 \mathrm{~m}$ este-oeste y $9,25 \mathrm{~m}$ norte-sur) con cuatro columnas exentas y sensiblemente equidistantes. La fachada al río sería la antigua alquibla, con una orientación cercana al sur $\left(161^{\circ}\right.$ respecto al norte) y muy parecida al significativo referente de la mezquita aljama $\left(151^{\circ}\right)$, aunque ambas se apartan bastante de lo ortodoxo para la ciudad $\left(100^{\circ}\right)^{30}$.

${ }^{27}$ El solar se recoge en los frustrados expedientes de realineación de 1868 y 1891 (AHM Ref. C-0768/112). Tampoco hay indicios de cambios en los planos urbanos anteriores (Karwinski, 1811 y Montis, 1851) o posteriores (1882 y 1926), hasta llegar a nuestros días.

28 Tomado del levantamiento urbano oficial (1996). Ayuntamiento de Córdoba, GMU.

${ }^{29}$ El grosor de los muros perimetrales se estima en $84 \mathrm{~cm}$ (1 vara), tal y como recogió el plano de 1753.

${ }^{30}$ Pese a la importante desviación, sabemos que el precepto se entendía de manera flexible. La hipótesis ortogonal es menos probable, ya que además de coincidir con la orientación cristiana, erraría hacia el Norte, algo sin precedentes en la ciudad e infrecuente en la península (Jiménez, "La Qibla extraviada"; Ríus, "La alquibla de Madīnat al-Zahrā"”; Calvo, "Las primeras mezquitas de al-Andalus"). 


\section{Formalización y tipo arquitectónico}

El espacio de la sala de oración se caracteriza por el doble sistema de arquerías ortogonales rotuladas en el dibujo, ambas con indicios de ser originales. Las norte-sur no ofrecen duda al ser perpendiculares a la qibla, secundando la costumbre local; también las este-oeste provendrían de la mezquita, ya que aunque parecen continuación del cuerpo de naves, éste es autónomo constructivamente y no existe correspondencia en la arquería más meridional ${ }^{31}$. Estamos, pues, ante la «[...] formazion de arcos» que aludía la primera descripción de 1725, términos que evidencian una organización arquitectónica más compleja que unas arquerías unidireccionales o «danças de $\operatorname{arcos}{ }^{32}$. Estas, además, implican habitualmente luces distintas para arcos y viguería de madera, que salva la distancia mayor.

El doble sistema de arcos se soportaría en cuatro columnas mar-

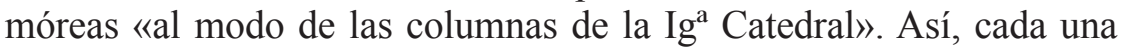
de ellas recibe arcos en las dos direcciones ortogonales, algo sin paralelo entre las mezquitas menores cordobesas y que pudo tomarse de la ampliación de la aljama realizada por al-Hakam II, el gran laboratorio de formas del arte califal (Fig. 8) ${ }^{33}$. Los nueve ámbitos cuadrados resultantes $(2,75 \times 2,60 \mathrm{~m})$ se cubrirían con bóvedas provenientes de la etapa islámica ${ }^{34}$, solución infrecuente en al-Andalus y sin preceden-

31 Aquí, además, se rotula un extraño «medio arco» acometiendo a la mitad de un vano, tal vez reelaboración de un arco islámico demolido al conectar la mezquita con el nuevo cuerpo de naves.

32 Ésta era la denominación habitual de líneas de arcos sobre columnas marmóreas, soportando techumbres de madera. Así, en 1589, la antigua mezquita de Santaella se describe: «... dicha yglesia que hera a la morisca de naves con danças de arcos y marmolejos de piedra. Los techos baxos de dança a dança de arcos. Su enmaderamiento viejo de madera a lo antiguo» (AGO Sec. Visitas Generales. Santaella, año 1589). También, una alusión de 1590 a la iglesia de Santa María de Cabra, antigua mezquita, alude a «... cinco nabes con cuatro danças de arcos de largo a largo. Los posteles e bazas de piedra colorada e algunos negros tenidos a lo morisco. Los techos baxos de madera labrada e tablazón...» (AGO Sec. Visitas Generales. Cabra, 1590).

${ }^{33}$ Las tres columnas más extremas de la arquería transversal que precede al miḥrāb son únicas, soportando arquerías bidireccionales. Esto se repetirá tardíamente en los baños cordobeses de Santa María (c/ Céspedes, 1) y de San Pedro (c/ Carlos Rubio), de cronología incierta pero posterior al siglo $\mathrm{x}$.

${ }^{34}$ Es poco probable que se tratara de bóvedas encamonadas añadidas en época cristiana, ya que éstas aparecen en las parroquias cordobesas aproximadamente a partir de 1730 .

Al-Qanțara XXXIII 1, 2012, pp. 83-106 ISSN 0211-3589 doi:10.3989/alqantara.2010.003 


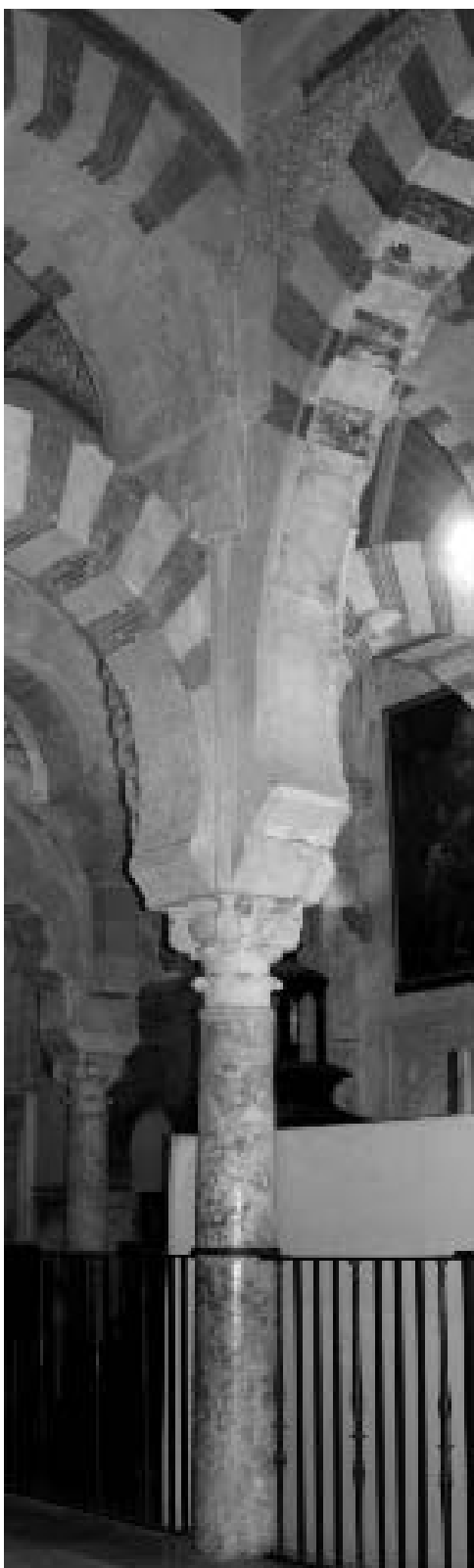

Figura 8. Arquerías entrecruzadas sobre una columna de la mezquita de al-Hakam II te entre las mezquitas locales ${ }^{35}$. Sin embargo, a escasos 700 metros encontramos un esquema similar, en el aljibe de Almanzor de la aljama, cuya planta de $14,5 \times 14,5 \mathrm{~m}^{36} \mathrm{se}$ compartimenta por arcos y cuatro pilares cruciformes en nueve ámbitos con bóveda de arista.

Dentro del conjunto de las mezquitas, la organización arquitectónica de nueve espacios, con cubriciones relativamente autónomas, permitiría incluir a la nuestra en el tipo denominado por Creswell como nine-dome-mosque ${ }^{37}$, de gran difusión geográfica pero con contados ejemplos conocidos. Los precedentes más cercanos serían los tunecinos de Bū Fatātā, en Sūsa

${ }^{35}$ Las conocidas secundan el esquema de naves contiguas cubiertas con madera y perpendiculares a la qibla. Incluso, las bóvedas de Santa Clara obedecen a una reforma cristiana bajomedieval (Marfil, Informe $y$ memoria cientifica). Sin embargo existen mezquitas abovedadas en la península, y es solución habitual en los baños; entre ellos, el sevillano de la c/ Mateos Gago, $n^{\circ} 1$, se formaliza como un ámbito cuadrado con cuatro columnas centrales (Valor, "Los baños").

36 Dimensiones según el plano (1981) del arquitecto G. Ruiz Cabrero (Nieto y Luca de Tena, La Mezquita de Córdoba, p. 138).

${ }^{37}$ Creswell, The Muslim Architecture of Egypt, vol. I, pp. 11-13 y Creswell, A Short Account of Early Muslim Arquitecture, 349351. Este autor le atribuyó un uso primordialmente funerario, algo que ha sido rebatido por estudios posteriores: King, "The Mosque of Bāb al-Mardūm", pp. 269-286; Ewert, "La mezquita de Bāb al-Mardūm"; un estudio más exhaustivo en la versión alemana (Ewert, "Die Moschee am Bāb al-Mardūm"). 
$(7,71 \times 7,86 \mathrm{~m})$, y en Qayrawān la Mezquita de las tres puertas $(9,05 \times 8,60 \mathrm{~m})$, esta de dimensiones similares a la nuestra ${ }^{38}$. También, la comparación con la primera sugiere que estamos ante una reinterpretación cordobesa del modelo ${ }^{39}$. Así, en vez de pilares ligeramente cruciformes, se utiliza la columna marmórea; y las bóvedas de cañón, que no contribuyen al entendimiento autónomo de cada ámbito, en Córdoba se debieron de cambiar por una solución más coherente espacialmente. En este sentido apuntan los dos paralelos peninsulares más claros, ambos en Toledo: la mezquita de Bāb alMardūm $^{40}$, de 6,60×6,60 m y nueve ámbitos cuadrados de 1,7 m de lado cubiertos por distintas cúpulas de arcos entrecruzados; y la de las Tornerías ${ }^{41}$, de 7,70 $\times 8,90 \mathrm{~m}$ y compartimentada en nueve rectángulos de $2,6 \times 2,1 \mathrm{~m}$. Junto al uso de la columna, con ambas podría compartir también el sistema de pilastras y arcos adosados perimetralmente, reconocibles en los dos lienzos no perforados del oratorio cordobés (meridional y oriental).

Todos estos indicios arquitectónicos, integrados con los datos recogidos en la descripción de 1727 , permiten formular una propuesta de reconstrucción espacial de la sala de oración. Según dicho documento, la altura libre interior de la mezquita sería de cuatro varas $(3,36 \mathrm{~m})$, un valor que se va a interpretar como una medida desde el suelo hasta la clave de los $\operatorname{arcos}{ }^{42}$; por encima de éstos se desarrollarían las bóvedas, que suponemos de arista en analogía con el alji-

38 Dimensiones en planta según Creswell, A Short Account, pp. 351 y 388. Otras mezquitas tempranas, aunque más alejadas son Sharîf Tabātabā (El Cairo, c. 950) o Sab'a wa-sab'īn Walī (Aswan, c. 1000). Consúltense otros ejemplos en King, "The nine bay domed mosque"; King, "The Mosque of Bāb al-Mardūm", p. 271; Ewert, "Die Moschee am Bāb al-Mardūm”. Según éste último, el tipo debió de ser frecuente en el camino de peregrinación a la Meca durante la época abbasí (fin siglo VIII al IX).

${ }^{39}$ G. King subraya la capacidad del tipo arquitectónico para, sin perder sus cualidades intrínsecas, adaptarse a las soluciones formales y constructivas de cada lugar. Esto explicaría también la utilización de la bóveda de cañón en Bū Fatātā, resultado según el autor de las tradiciones constructivas tunecinas de ascendencia romana (King, "The Mosque of Bāb al-Mardūm", pp. 270-274).

${ }^{40}$ Es fundada por Ahmad b. al-Hadīdī en el 999. Su conversión a iglesia de la Santa Cruz, actual Cristo de la Luz, está estudiada y documentada por Calvo, "La mezquita de Bāb al-Mardūm".

${ }^{41}$ Aunque de cronología discutida, se levantaría en el siglo XII, secundando el tipo de Bāb al-Mardūm.

${ }^{42}$ En este orden de valor están las flechas del aljibe de Almanzor, (3,8 m), la mezquita de Bāb al-Mardūm (3,60 m), o la de al-Qanātị (Puerto de Santa María, Cádiz) (3,50-3,65 $\mathrm{m}$ en una dirección y 4,18-4,30 m en la ortogonal) (Jiménez, "El Castillo de San Marcos"). 
be de Almanzor. Con estas premisas, y teniendo en cuenta el esquema de las dos mezquitas toledanas, se plantea la hipótesis dibujada en la Fig. 9. Según esta, la altura de las claves de las bóvedas, y en definitiva la altura máxima interior, sería de $5,05 \mathrm{~m}^{43}$; este valor, tras la asignación de espesores, rondaría exteriormente los 5,5 m, a partir de los cuales se desarrollaría la cubrición ${ }^{44}$.

Pese a las similitudes con la planta de Bāb al-Mardūm, el desarrollo en altura es sustancialmente inferior a sus $9,5 \mathrm{~m}$, obtenidos al sobreelevar las bóvedas mediante cuerpos prismáticos con huecos de inspiración califal. Tanto en la espacialidad, como posiblemente en la riqueza decorativa, nuestro edificio debió de ser más modesto ${ }^{45}$. Sin embargo, al igual que el toledano, podríamos estar ante un oratorio originado por una fundación pía, utilizado también para fines educativos, algo coherente con un espacio cuadrado y bastante diáfano por el uso de la columna ${ }^{46}$.

\section{Referentes arquitectónicos y cronología}

Sin nuevos hallazgos documentales, o un estudio arqueológico, carecemos de muchos elementos de juicio para datar el edificio, aunque por sus características es posible acotar un período temporal. Fuera de la península, las citadas mezquitas norteafricanas de Sūsa (838-841) y Qayrawān (866) son el precedente más claro del modelo arquitectónico, pese a las diferencias comentadas. Sin embargo, debe tenerse en cuenta que en la etapa emiral escasearon las soluciones abovedadas ${ }^{47}$, lo que aconsejaría retrasar el límite cronológi-

${ }^{43}$ Supera los 4,70 m del aljibe de Almanzor, cuyas bóvedas arrancan más bajas. Sin embargo, no llega a los 6,60 m de las Tornerías o a los 5,94-6,15 m de al-Qanātir.

${ }^{44}$ En la volumetría de la iglesia que dibujó Wyngaerde (1567), que aún incluía la mezquita por cabecera, se pueden estimar entorno a 6 metros hasta la cornisa.

${ }^{45}$ En vez de ladrillo pudo construirse con piedra, aludida en la descripción de 1727. Es significativo que Wyngaerde (1567) lo dibuje como un volumen liso, sin composición arquitectónica alguna.

${ }^{46}$ El oratorio toledano pudo ser simultáneamente un centro de enseñanza ligado a la familia del fundador, según Calvo, "La mezquita de Bāb al-Mardūm", pp. 321323 y Calvo, "Reflexiones sobre la mezquita de Bāb al-Mardūm". También pudo ser el caso de la mezquita egipcia de Sharīf Tabātabā, según Sour-del-Thomine, "Locaux d'enseignement". Todo esto es coherente con la hipótesis de G. King de que este tipo arquitectónico era promovido por destacados personajes de la sociedad islámica (King, "The nine bay domed mosque", p. 386).

47 Jiménez, "Compendio de la arquitectura emiral", p. 474. 

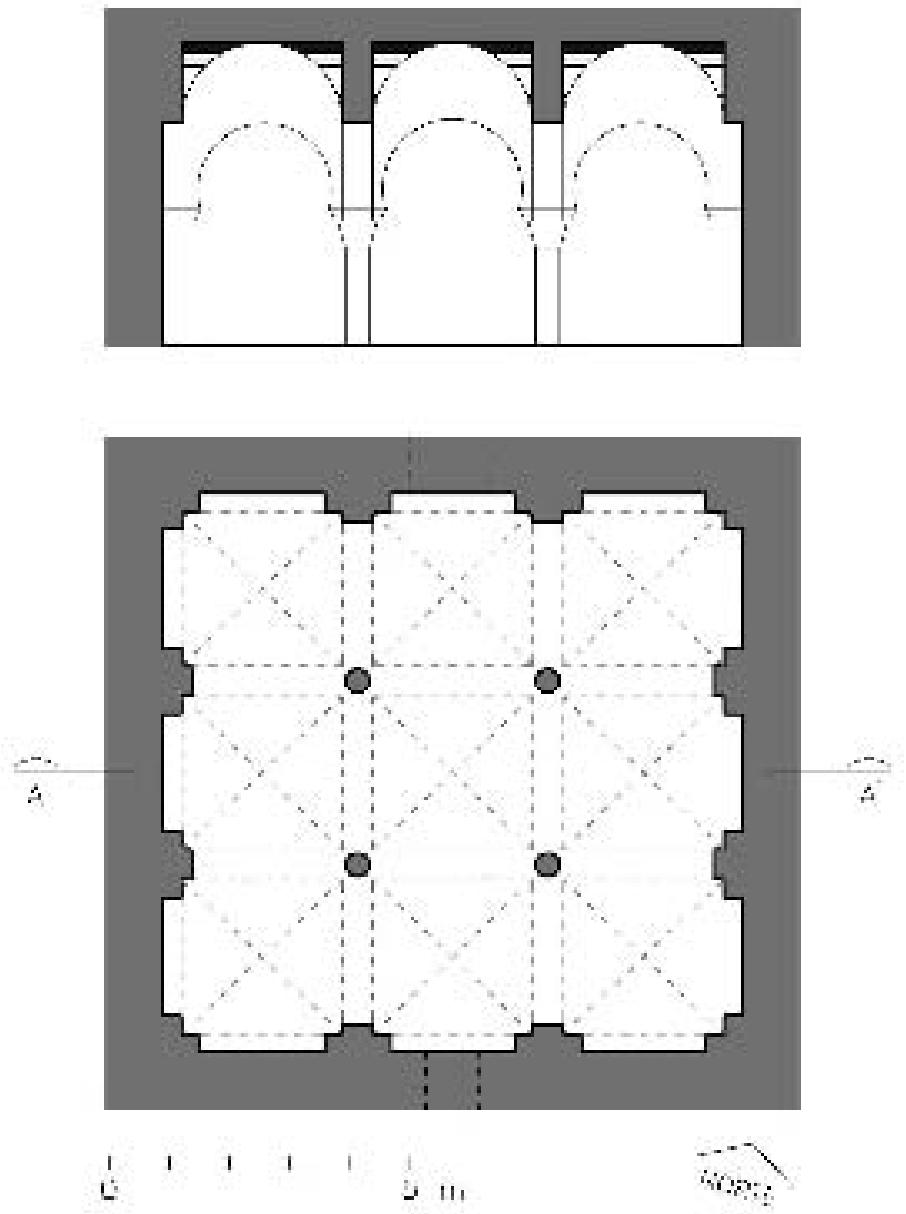

Figura 9. Hipótesis de la sala de oración de la mezquita (huecos de acceso y del mihrāb grafiados en línea discontinua)

co inferior hasta el siglo X. Respecto al superior, tampoco es probable una datación excesivamente tardía, porque se utilizan columnas en vez de pilares cuadrados o rectangulares, más frecuentes a partir del siglo XII. Incluso sería muy discutible la adscripción al siglo XI, dado el importante decaimiento urbano que se produce en Córdoba a raíz de la fitna; es significativo, en este sentido, que ninguna de las mezquitas cordobesas conocidas es posterior a este momento. 
Dentro de la etapa califal se podría precisar incluso un período más limitado. Este abarcaría desde los años de la ampliación de la aljama por al-Hakam II (962-966), posible referente para la columna única soportando arcadas bidireccionales, hasta el año 999, fecha de la inscripción fundacional de la mezquita toledana de Bāb al-Mardūm, el paralelo más claro en la península. Aunque está admitido que esta se inspira en las formas califales de la aljama cordobesa ${ }^{48}$, la existencia de un edificio como el estudiado abre la posibilidad de que estemos ante un paso intermedio, que constituiría un modelo más cercano y coetáneo que los ejemplos norteafricanos ${ }^{49}$. El pequeño oratorio de barrio cordobés, u algún otro similar, bien pudo constituir un antecedente del toledano; si no para la variedad y riqueza formal de las cúpulas, sí al menos para el tipo arquitectónico, un edificio cuadrado con nueve sectores abovedados sobre columnas. Esto justificaría su cronología a caballo entre estos dos señalados edificios, otorgándole un importante papel dentro de la arquitectura islámica peninsular.

Todo esto suscita una última reflexión. Si el oratorio toledano se inspiró en el cordobés, ¿de dónde tomó este el tipo arquitectónico?, ¿existieron más ejemplos en la ciudad? De momento no existe indicio alguno entre las mezquitas conocidas; y aunque apareciera, estamos en definitiva ante la asunción de un modelo foráneo, cuyo origen último se cree oriental. Córdoba, de nuevo, habría sido vía de acceso, acomodo y foco de algunas de las más significativas novedades hispanas, ejerciendo su hegemonía arquitectónica y artística en el al-Andalus del siglo X.

\section{Conclusiones}

El caso aquí estudiado es prueba manifiesta de cómo, y con qué escasas transformaciones, se adaptarían inicialmente las mezquitas a

${ }^{48}$ Ewert, "Die Moschee am Bāb al-Mardūm". Ténganse también en cuenta los vínculos que el fundador, Ahmad ibn al-Hadīè̄, debía de tener con el poder cordobés, ya que incluso acudió en el año 976 a la proclamación del califa Hišām II (Calvo, "Reflexiones sobre la mezquita", p. 338).

${ }^{49}$ G. King precisa que la reconocida influencia formal de la mezquita de al-Hakam II debe distinguirse de la tipológica, que secundaría un difundido modelo foráneo, sin antecedentes peninsulares. En este sentido, desde que L. Golembek relacionó el oratorio toledano con la mezquita de Sharif Tabataba (El Cairo, c. 950) se han sucedido las hipótesis, apuntando a un origen oriental. Sin embargo, como concluye G. King, de momento no se conoce el edificio en el que pudo inspirarse (Golembek, "Abbasid Mosque at Balkh"; King, "The Mosque of Bāb al-Mardūm”, p. 269-278). 
iglesias. No obstante, cuando el conquistador cristiano pudo erigir una nueva fábrica, la gran mayoría desaparecieron. Bajo este punto de vista, nuestra mezquita es un tanto singular al sobrevivir casi cinco siglos alojando el culto cristiano. A ello contribuiría su sólida conformación, un edificio compacto y masivo, muy diferente a las estructuras de arquerías paralelas, con tendencia a la inestabilidad y soportando perecederas cubiertas de madera.

La mezquita debió de tener una orientación aproximada al sur ( $161^{\circ}$ respecto al norte), sensiblemente similar a la de la aljama. Su sala de oración sería un seudo-cuadrado de 9,60 m $\times 9,25 \mathrm{~m}$, compartimentado por cuatro columnas y un doble sistema de arcadas ortogonales en nueve ámbitos abovedados de $2,75 \times 2,60 \mathrm{~m}$. Esto encuadra a la mezquita en un tipo arquitectónico que cuenta con algunos tempranos ejemplos norteafricanos y dos en Toledo, aunque es infrecuente en la península y no se conoce paralelo en Córdoba. Presumiblemente, en la ciudad se habría importado y adaptado el modelo de «nine-dome-mosque», de ascendencia oriental, constituyendo la arquitectura local, una vez más, cauce de lejanas influencias.

Nuestro pequeño oratorio debió erigirse durante el último tercio del siglo $\mathrm{X}$, ya que sus características arquitectónicas lo convierten en interesante paso intermedio entre Bāb al-Mardūm(999) y el referente atribuido tradicionalmente a ésta, la ampliación califal de la mezquita aljama (962-66). Pese a que debió de ser un edificio más modesto, estaríamos ante un precedente más cercano y expreso que los hasta ahora propugnados para el ejemplo toledano, que lo relacionaban con mezquitas foráneas, o con construcciones tan distintas como baños, aljibes o incluso iglesias del prerrománico hispano. La hipótesis refuerza y completa la filiación cordobesa de Bāb al-Mardūm, que así encontraría en la arquitectura de la ciudad todo lo necesario para su concreción, tanto en forma y decoración, como en una organización arquitectónica ya probada. Esto último, a la postre, arroja nueva luz sobre un problema recurrente en la historiografía del oratorio toledano.

Aún con escasos datos documentales, la existencia de la mezquita es innegable. Aquí se ha intentado recopilar toda la información disponible, de la que deriva una propuesta de restitución gráfica del primitivo oratorio islámico. Sin embargo, las hipótesis sobre su formalización arquitectónica deben considerarse abiertas, siendo necesario profundizar aún más en las fuentes documentales cristianas e islámicas, 
o quizás reinterpretar lo ya conocido, a la luz de lo aportado en este trabajo. Sin duda, un estudio arqueológico también permitiría avances sustanciales, ya que las demoliciones de 1725 no debieron arrasar totalmente los arranques de la mezquita. Esta es posible que aún esté ahí, en un subsuelo inalterado, a la espera de ser excavada (Fig. 10).

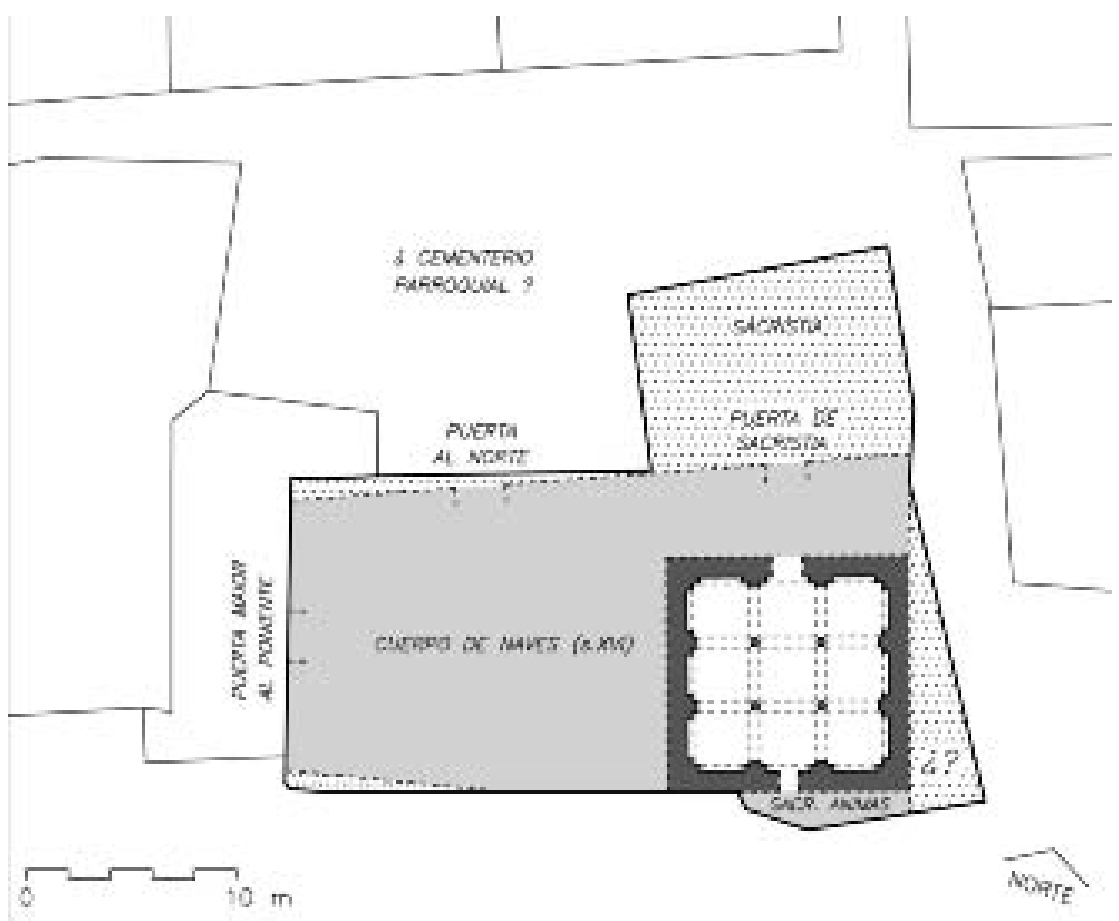

Figura 10. Planta propuesta de la sala de oración de la mezquita, insertada en el parcelario actual, con las indicaciones del Libro de Bautismos 1707-1727

(textos y dibujo del edificio en fol. 451 y 451vta.)

\section{Bibliografía}

Bosch, J., Historia de Sevilla. La Sevilla Islámica, Sevilla, Universidad, 1984. Bueno, M. L., "Fuga Demonium, Angeli Pacis ingresus. El ritual litúrgico romano-galicano en el proceso de transformación de espacios sacros: de la mezquita a la iglesia (XI-XIII)", en Jiménez, A. (ed.), Actas del simposium internacional sobre la Catedral de Sevilla en el contexto del gótico final, Sevilla, Taller Diregeo, S. L., 2007, vol. II, pp. 261-280. 
Calvo, S., "La mezquita de Bāb al-Mardūm y el proceso de consagración de pequeñas mezquitas en Toledo (siglo XI-XIII)", Al-Qantara, XX, 2 (1999), pp. 299-331.

Calvo, S., "Las primeras mezquitas de al-Andalus a través de las fuentes árabes (92/711-170/785)", Al-Qantara, XXVIII, 1 (2007), pp. 143-179.

Calvo, S., "Reflexiones sobre la mezquita de Bāb al-Mardūm y la Capilla de Belén de Toledo", en Entre el Califato y la Taifa: Mil años del Cristo de la Luz. Actas del Congreso Internacional. Toledo, 1999, Toledo, Asociación de Amigos del Toledo Islámico, 2000, pp. 335-346.

Calvo, S., Urbanismo en la Córdoba islámica, Madrid, Edilupe Ediciones, S. L., 2002, pp. 85-88.

Creswell, K. A. C., A short account of early Muslim Arquitecture, Aldershot, Scholar Press, 1989.

Creswell, K. A. C., The Muslim Architecture of Egypt, Oxford, The Clarendon Press, 1952.

Ecker, H. "How to administer a conquered city in al-Andalus: Mosques, parish churches and parishes", en Robinson, C. y Rouhi, L. (ed.), Under the influence: Questioning the comparative in Medieval Castile, Leiden, Brill, 2004, pp. 41-65.

Ecker, H., "The conversión of Mosques to Synagogues in Seville: The Case of the Mezquita de la Judería", Gesta, 36, 2 (1997), pp. 190-207.

Ecker, H., "The great Mosque of Córdoba in the twelfth and thirteenth centuries", Muqarnas, 20 (2003), pp. 113-141.

Ewert, C., "Die Moscheee am Bab al-Mardum in Toledo. Eine "Kopie" der Moschee von Córdoba", Madrider Mitteilungen, 18 (1977), pp. 287-354.

Ewert, C., "La mezquita de Bāb al-Mardūm de Toledo (Cristo de la luz): Una "copia" de la mezquita de Córdoba", en Entre el Califato y la Taifa: Mil años del Cristo de la Luz. Actas del Congreso Internacional. Toledo, 1999, Toledo, Asociación de Amigos del Toledo Islámico, 2000, pp. 11-52.

Gámiz, A., "Paisajes urbanos vistos desde globo: dibujos de Guesdon sobre fotos de Clifford hacia 1853-55", Ega, 9 (2004), pp. 110-117.

García Franco, S., La legua náutica en la Edad Media, Madrid, Instituto Histórico de la Marina, 1957.

Golembek, L., “Abbasid Mosque at Balkh”, Oriental Art, 15, 3 (1969), pp. 173-189.

Gómez, J., Catálogo de los Obispos de Córdoba, y breve noticia histórica de su Iglesia Catedral, y Obispado, Córdoba, Juan Rodríguez, 1778.

Guesdon, A., L'Espagne a vol d'ouaseau, París, Hauser y Delarue, 1853-55.

Jiménez, A., "Compendio de la arquitectura emiral cordobesa", en Creswell, K. A. C., Compendio de arquitectura paleoislámica, Sevilla, Universidad, 1979.

Jiménez, A., "El Castillo de San Marcos", en Nuestros orígenes históricos como el Puerto de Santa María, Cádiz, Centro del Patrimonio Histórico, 1988, pp. 35-52.

Jiménez, A., "La Qibla extraviada", Cuadernos de Madinnat al-Zahrā', 3 (1991), pp. 189-209.

Al-Qanțara XXXIII 1, 2012, pp. 83-106 ISSN 0211-3589 doi:10.3989/alqantara.2010.003 
King, G., "The Mosque of Bāb al-Mardūm and the Islamic building tradition", en Entre el Califato y la Taifa: Mil años del Cristo de la Luz. Actas del Congreso Internacional. Toledo, 1999, Toledo, Asociación de Amigos del Toledo Islámico, 2000.

King, G., "The nine bay domed mosque in Islam", Madrider Mitteilungen, 30 (1989), pp. 333-390.

Laguna, T., "La aljama cristianizada: Memoria de la Catedral de Santa María de Sevilla", en Morales, A. J. (ed.), Metrópolis totus hispaniae: 750 aniversario de la incorporación de Sevilla a la corona castellana, Sevilla, Ayuntamiento, 1998, pp. 41-89.

Luna, D. y Zamorano, A. M., "La mezquita de la Antigua finca El Fontanar (Córdoba)", Cuadernos de Madinnat al-Zahrā', 4 (1999), pp. 145-173.

Madrazo, P., Recuerdos y bellezas de España, Madrid, Repullés, 1855.

Marfil, P., Informe y memoria científica de intervención arqueológica de urgencia. Iglesia del convento de Santa Clara, c/Rey Heredia de Córdoba, Córdoba, 1996 (inédito).

Montes Romero, I. y Valor, M., "De mezquitas a iglesias; el caso de Sevilla", en Boe, G. de y Verhaeghe, F., Religion and belief in medieval Europe, Zellik, 1997, Papers of the "Medieval Europe Brugge 1997" conference IV, pp. 139-148.

Nieto, M., Corpus medievale cordubense. 1256-1277, Córdoba, Monte de Piedad y Caja de Ahorros, 1980.

Nieto, M., Historia de la Iglesia en Córdoba II. Reconquista y Restauración (1146-1326), Córdoba, Monte de Piedad y Caja de Ahorros, 1991.

Nieto, M. y Luca de Tena, C., La Mezquita de Córdoba: planos y dibujos, Córdoba, Colegio Oficial de Arquitectos de Andalucía Occidental, 1992.

Ramírez de Arellano, T., Paseos por Córdoba, Córdoba, Imprenta de D. Rafael Arroyo [1873] 1985.

Ríus, M., "La alquibla de Madīnat al-Zahrā’ y otras mezquitas andalusíes", en Viguera, M. J. y Castillo, C. (coord.), El esplendor de los Omeyas cordobeses. La civilización musulmana de Europa Occidental, Granada, El Legado Andalusí, 2001, vol. I, pp. 424-30.

Sour-del-Thomine, J., "Locaux d'enseignement et madrasas dans 1'Islam medieval", Revue des études islamiques, XIV, (1976), pp. 195-196.

Taylor, I. J., Voyage pittoresque en Espagne, en Portugal et sur de la côte d'Afrique, de Tanger à Tetouan, París, A. F. Lemaître Éditeur [1826] 1860.

Valor, M., "Los baños", en Valor, M. (coord.), El último siglo de la Sevilla islámica (1147-1248), Sevilla, Universidad, 1995, pp. 185-188.

Recibido: 18/07/2010

Aceptado: 30/05/2011

Al-Qanțara XXXIII 1, 2012, pp. 83-106 ISSN 0211-3589 doi:10.3989/alqantara.2010.003 